\title{
DOS JORNAIS-FAX DE MOÇAMBIQUE ÀS POTENCIALIDADES DOS WEB-JORNAIS
}

\author{
FERNANDo Zamith*
}

\section{Introdução}

A procura de formas alternativas de fazer um jornal sempre foi algo que me interessou. As limitações do jornal tradicional, simultaneamente exposto a variações do mercado publicitário e do volume de vendas e dependente de um parque gráfico e de uma rede de distribuição, constituem, na minha perspectiva, uma das principais causas das sucessivas (para não dizer permanentes) crises da imprensa, particularmente a portuguesa.

Para evitar tanta dependência de factores fundamentalmente exterInos e, ao mesmo tempo, reduzir custos, nada melhor do que eliminar algumas daquelas componentes tradicionais da produção e distribuição de um jornal.

Jornais gratuitos, de difusão por fax e de busca na Internet são algumas experiências que me proponho analisar e que poderão ser exploradas como alternativas de auto-emprego para recém-licenciados em Comunicação Social.

Importa notar que esta comunicação não resulta, de forma alguma, de um trabalho de investigação. Constitui apenas uma pequena compilação de ideias e experiências. 


\section{Os jornais gratuitos}

Uma das minhas primeiras experiências profissionais foi numa publicação que introduziu um elemento inovador na imprensa portuguesa, cortando precisamente uma das componentes tradicionais de distribuição de um jornal: a venda. Falo do (saudoso) Metro, o jornal/revista do Porto lançado em 1988 pelos irmãos Nuno e Paulo Arbunhosa e que, infelizmente, já não existe, após muitos anos de "resistência» e tentativas de adaptação às condições do mercado e aos interesses dos leitores.

Dirigido em particular aos frequentadores da "noite portuense», o Metro fornecia quinzenalmente um roteiro das actividades culturais e recreativas programadas para a cidade, a par de artigos e reportagens sobre temas variados da vida do Porto, como música, teatro, cinema, pintura, dança e moda, E também sobre os bares e discotecas onde era oferecido.

Após ter colaborado nos primeiros números do Metro, transferi-me para um projecto concorrente de existência efémera, o jornal Grátis, dirigido pelo primeiro chefe de redacção do Metro, Daniel Guerra. Mais tarde, eu mesmo liderei um outro projecto $(\mathrm{Palco})$, que não chegou sequer a ser impresso, desta vez por dificuldades dos promotores na angariação de publicidade, única fonte de receita deste tipo de jornais.

Apesar dos fracassos destes projectos e de outros da mesma época, como o desportivo Drible, lançado por alunos da Escola Superior de Jornalismo, do Porto, foi aberta uma nova via de produção de jornais, que hoje adquire um novo "fôlego" com as restrições introduzidas pelo Governo à distribuição de panfletos de publicidade nas caixas de correio.

Adaptando-se às novas condições, surgiram recentemente, sobretudo em Lisboa e Porto, jornais e revistas de cariz marcadamente publicitário e que podem ser colocados nas caixas de correio «amarelas» (com autocolantes "Publicidade Aqui Não»). Se é verdade que é a publicidade que «domina» este tipo de publicações, também é certo que ela não condiciona de todo o trabalho jornalístico, sendo mesmo possível oferecer-se um produto com alguma qualidade e que cative os leitores. Exemplo disso são as revistas "Viva» que surgiram este ano em várias zonas das cidades de Lisboa e do Porto.

\section{Os jornais-fax de Moçambique}

Projectos alternativos extremamente interessantes que tive oportunidade de acompanhar de perto são os jornais de difusão por fax de Moçambique.

Nos dois anos (entre Dezembro de 1995 e Dezembro de 1997) que estive em Maputo como delegado da Agência Lusa, foram lançados três 
novos jornais-fax (um quarto, vespertino, não vingou), Diário de Negócios, Correio da Manhã e Metical, que se vieram juntar aos pioneiros Mediafax e Imparcial.

Foi um período muito rico (que julgo que teve continuidade), em que os jornalistas moçambicanos provaram que, numa jovem democracia de um país africano pobre, é possível ter uma imprensa independente dos poderes político e económico.

Com poucos meios, todos os dias úteis eram produzidos cinco pequenos jornais (de três a seis páginas A4) por cinco pequenas equipas, nalguns casos com apenas três ou quatro jornalistas.

O mercado destes jornais-fax moçambicanos está sobretudo em embaixadas, organizações não governamentais e grandes empresas, mas abrange também organismos públicos, quadros superiores, instituições culturais e um leque variado de outros profissionais. As únicas condições para se ser cliente destes jornais são ter um aparelho de fax e poder pagar uma soma que, não sendo baixa, pudesse ser compensada pelo acesso diário a informação e opinião independentes que o único jornal diário clássico publicado naquele período em Maputo, o "Notícias», de tendência prógovernamental, não fornecia.

Enquanto o "Notícias» custava 4.000 meticais (cerca de 56 escudos), a assinatura mensal dos jornais-fax custava entre 20 e 40 dólares norte-americanos, o que correspondia (ao câmbio de então) a um preço unitário de 180 a 360 escudos, que centenas de instituições estavam dispostas a pagar.

Os principais jornais-fax de Maputo tinham então cerca de 300 assinantes, que eram «alimentados» por vários aparelhos de fax durante toda a madrugada. Isto permitia que os clientes encontrassem no seu gabinete logo que lá chegassem a(s) edição(ões) do dia do(s) seu jornal(is)-fax.

À semelhança destes projectos privados locais, também as agências noticiosas de Moçambique (AIM) e Portugal (Lusa) difundiam diariamente (de segunda a sexta-feira) boletins, com distribuição por fax e ao domicílio.

A experiência que adquiri na edição do Boletim Lusa de Maputo permitiu-me perceber melhor as vantagens e desvantagens deste tipo de jornais.

Como vantagens, destaco desde logo os baixos custos de instalação (investimento) e de produção. Com menos de mil contos, é possível criar uma estrutura mínima de produção e distribuição de um jornal-fax.

A equipa de jornalistas pode ser também pequena, porque é inviável distribuir por fax um jornal com mais de seis páginas. A produção do jornal-fax é toda feita em computador (texto, grafismo e imagem) e com três ou quatro linhas de fax é possível distribuir centenas de jornais num horário de baixo custo (madrugada).

O fecho da edição pode ser feito às 23 ou 24 horas, o que significa ganhos comparativos face aos jornais tradicionais. Acresce ainda, como já destaquei, que o cliente tem o jornal no seu escritório quando lá chega de 
manhã, não necessitando de o comprar na rua ou de esperar que chegue o correio ou o paquete da distribuição.

As desvantagens são, desde logo, o reduzido mercado (só quem tem fax é que pode ser cliente) e a limitação de espaço (cada jornal tem apenas seis a 12 textos). Os custos de distribuição não são muito elevados, mas são fixos, isto é, não diminuem proporcionalmente com o aumento de clientes, como acontece com os custos de produção.

Outra desvantagem é o facto de o jornal ser facilmente reproduzível, pelo que várias pessoas podem ter acesso a cópias (entregues em mão ou também enviadas por fax) do único exemplar pago.

\subsection{Breve história e descrição de conteúdo}

Apesar da escassez de meios, os jornais-fax moçambicanos conseguem ter, na generalidade, uma qualidade razoável, atestadas pela fidelidade de um leque de leitores que não deixam de ser exigentes, apesar de sabermos que a oferta de informação em Moçambique é ainda muito reduzida, quando comparada com o que existe em países do chamado «Primeiro Mundo».

Criado em 1992 por uma cooperativa de experientes jornalistas (Mediacoop), o Mediafax conquistou rapidamente um espaço nobre na imprensa moçambicana, transformando-se num título de referência e de leitura "obrigatória». Nos primeiros anos de publicação, o Mediafax viveu sobretudo do carisma do seu editor, Carlos Cardoso, ex-director da Agência de Informação de Moçambique e que, tal como muitos outros jornalistas moçambicanos, se afastara do círculo dos apoiantes do poder, passada que fora a euforia pós-independência. Este estatuto de jornalista independente que Carlos Cardoso criou reflectiu-se no Mediafax, dando aos leitores do jornal garantias de que, na generalidade, as notícias eram verdadeiras, credíveis e não tendenciosas.

Se a relação com o poder político (e mesmo em relação à Renamo e a outros partidos da oposição) teve resultados positivos, o mesmo já não se poderá dizer em relação a algumas empresas privadas, sendo notável o excessivo espaço dado por Carlos Cardoso aos seus textos de opinião, em que roçava um certo "fundamentalismo» económico.

Com a saída de Carlos Cardoso, em 1997, o Mediafax ressentiu-se um pouco, até porque outros jornalistas se transferiram com o editor para um novo jornal-fax, o Metical (nome da moeda moçambicana). Contudo, o novo editor, Fernando Veloso, conseguiu dar ao Mediafax um segundo "fôlego", criando-se uma saudável concorrência, à qual entretanto se tinha juntado outro título, o Correio da Manhã. 
O segundo jornal-fax a surgir em Moçambique, em 1994, foi o Imparcial, com uma ténue ligação ao homónimo angolano, mas com uma redacção e edição completamente autómona. Por ironia (ou talvez não), o Imparcial era, pelo menos nos anos em que o li quotidianamente, o mais parcial dos jornais-fax moçambicanos, com uma exagerada e demasiado visível tendência pró-Renamo.

O surgimento do Correio da Manhã, no início de 1997, constituiu uma «lufada de ar fresco», nomeadamente no grafismo e na distribuição alternativa por correio electrónico, mas o nível editorial baixou pouco tempo depois, com a saída do seu fundador, Leandro Paul.

O Diário de Negócios, lançado em 1996, nunca se conseguiu impor. As suas lacunas e fragilidades foram sempre notórias, com destaque para o seu quadro de jornalistas, reduzido, sem experiência e de pouca qualidade. Raras vezes este jornal conseguiu divulgar verdadeiras novidades, notando-se frequentemente que era com dificuldade que preenchia o seu mínimo diário (três páginas), amiúde recorrendo a textos alheios. Como agravante, o Diário de Negócios enveredou por caminhos pouco recomendáveis, de uma certa xenofobia, à semelhança do que aconteceu na segunda fase do Correio da Manhã.

Apesar destes vários «pecados deontológicos» e da exiguidade de meios materiais e humanos de qualidade, o desenvolvimento destas experiências privadas de jornais-fax foi extremamente positiva para a imprensa moçambicana, conferindo-lhe o equilíbrio necessário entre a informação oficial dos jornais controlados pelo poder político e a "visão alternativa» da imprensa independente, que conheceu nos últimos anos também um grande impulso nos jornais tradicionais, sobretudo semanários.

Outro aspecto curioso, paralelo ao fenómeno dos jornais-fax moçambicanos, foi a publicação de boletins diários por parte das agências noticiosas moçambicana (AIM) e portuguesa (Lusa).

Relativamente ao Boletim Lusa difundido em Maputo, aquele que, naturalmente, melhor conheço, surgiu ainda durante a guerra civil, período em que escasseavam as informaçōes, quer sobre o conflito quer sobre o que se passava fora do país. $\mathrm{O}$ Boletim Lusa ainda hoje se publica de segunda a sexta-feira, com uma distribuição predominantemente por fax, mas ainda também ao domicílio. Nas quatro páginas diárias, sem gravuras nem publicidade, este boletim apresenta uma selecção das notícias de todo o Mundo difundidas pela Lusa, com destaque para as que dizem respeito a Moçambique e à restante África Austral. 


\section{Os "web-jornais"}

A evolução tecnológica abriu novas portas à comunicação social, trazendo consigo inovações constantes, que ainda hoje não estão a ser aproveitadas na sua capacidade total.

A evolução das tecnologias multimedia e, paralelamente, a rápida expansão da Internet, criaram condições para o surgimento de um novo tipo de meios de comunicação social, os «web-jornais». Primeiro foram os jornais tradicionais (principalmente os diários) que criaram ediçōes próprias na Internet, depois as rádios e televisões seguiram o mesmo caminho e agora já há em Portugal um jornal que apenas está disponível na Internet, o Diário Digital.

Lançado em 19 de Julho último, o Diário Digital soube apostar num nicho de mercado que as chamadas «edições electrónicas dos jornais não tinham explorado. Vivendo apenas das receitas publicitárias, este jornal colocou-se num espaço até então vazio, ao actualizar permanentemente as suas duas edições diárias. Desta forma, o Diário Digital não só marcou uma posição como ousou desafiar outros órgãos de informação, testando uma certa concorrência com as rádios, televisões e agências noticiosas, sem se esquecer de aproveitar outra das grandes vantagens da Internet, a disponibilização em arquivo de todas as edições anteriores.

Um jornalista, um computador portátil com modem e um telemóvel é o suficiente para que, com grande rapidez, as notícias possam chegar à «redacção» (até o tradicional conceito de redacção foi posto em causa) de um «web-jornal» e a qualquer momento possam ser editadas e difundidas.

No dia do lançamento, o director do Diário Digital, Luis Delgado, referiu que os estudos de mercado encomendados pelos promotores do projecto apontavam para uma quota de publicidade de três a quatro por cento para os «web-jornais», o que revela as potencialidades que este tipo de meio já proporciona.

A reduzida equipa redactorial com que o Diário Digital surgiu (12 jornalistas) denota, contudo, alguma precauçāo e demonstra que o "ataque» à concorrência de outro tipo de media só poderá ser feito mais tarde, dada a estrutura que cada um desses «concorrentes» tem.

O aparecimento deste primeiro «web-jornal» português veio, definitivamente, julgo eu, provar aos mais cépticos que a Internet não veio necessariamente "matar» os jornais e pôr em perigo os postos de trabalho dos jornalistas.

Os jornais de papel sobreviveram à expansão dos audio-visuais e vão sobreviver também a esta revolução tecriológica. Não podem, contudo, ignorar as novas condições do mercado. Ainda este mês o Finantial Times anunciou a actualização permanente ( 24 horas por dia) da sua edição electrónica (projecto que implica a contratação de 100 novos jornalistas) 
e o diário espanhol $E l$ Mundo. lançou uma segunda ediçāo vespertina, exclusivamente disponível na Internet.

$\mathrm{O}$ que os jornais de papel têm de fazer é baixar os preços das suas ediçōes em papel (em Portugal, os primeiros passos já foram dados com a redução para 100 escudos do preço da maioria dos diários) e simultaneamente apostar em força nas chamadas «edições electrónicas» (na Internet). Com a redução do preço de capa, poderão aumentar a tiragem e, com isso, justificar um aumento nas tabelas de publicidade e baixar os custos de produção por unidade.

Com o desenvolvimento das edições na Internet, os jornais diversificam a sua oferta e conseguem uma nova fonte de receita publicitária. O resultado de tudo isto será, a meu ver, um maior número de leitores de jornais, melhores perspectivas para os proprietários da imprensa e para os novos investidores e alguma esperança de intensificação da procura de jornalistas.

É claro que este panorama optimista não pode ser visto separadamente de outros fenómenos, que no caso português estão a ter desenvolvimentos bem mais sombrios para os actuais e futuros jornalistas. Refiro-me à excessiva concentração de órgãos de comunicação social em três ou quatro grupos empresariais e o ainda mais excessivo número de licenciados que as universidades "produzem» anualmente para o sector.

Este último fenómeno está, ao mesmo tempo, a lograr as expectativas de muitos jovens (que acabam por ir para o desemprego ou para outras profissões) e a degradar as condições salariais de quem trabalha no sector, independentemente da sua experiência, capacidade, profissionalismo e qualificações académicas.

É pelo exposto anteriormente que considero que a solução para alguns dos problemas referidos está na imprensa alternativa, de certa forma liderada neste momento pelas potencialidades que a Internet veio proporcionar, rompendo um dos obstáculos tradicionais mais importantes, o da distribuição.

A experiência do Diário Digital não é, de forma alguma, redutora e acabada. Muito mais pode ainda ser explorado pelos «web-jornais». A especialização será, na minha perspectiva, um dos mais viáveis e interessantes caminhos a seguir. Porque não um «web-jornal» só sobre cultura?... ou automóveis... ou moda... ou economia... ou coleccionismo. E porque não um «web-jornal» local ou regional? Só com notícias, por exemplo, do Minho, Trás-os-Montes, Alentejo ou Madeira. E que possa ser lido em Braga, Lisboa, Paris, Joanesburgo, Caracas, Nova Iorque e Montreal.

Ou então um «web-jornal» em língua portuguesa sobre Àfrica ou sobre o espaço lusófono, que chegasse a todos os países onde a Internet já chega e que fosse feito por jornalistas dos oito países de língua portuguesa e 
lido simultaneamente no Porto, em Maputo, na Cidade da Praia, no Rio de Janeiro e em Díli.

\section{Conclusão}

A evolução das tecnologias da informação está a abrir inúmeras portas aos comunicadores sociais, que permitem romper com alguns obstáculos tradicionais que se deparam a quem quer ou já está a trabalhar nesta área.

Os leitores/consumidores de jornais estão progressivamente a mudar os seus hábitos. Hoje já muitos consultam as edições electrónicas dos jornais nos seus computadores enquanto tomam o pequeno almoço, dando ordens de impressão apenas aos artigos que lhes interessam.

Não estar atento a este fenómeno é deixar-se ultrapassar pelos outros e pelo tempo. Não estar atento a este fenómeno poderá não ser fatal, mas será, com certeza, um rude golpe.

A tecnologia não constitui, no entanto, a resposta a todas as necessidades. O «segredo» está em saber potenciar os pontos fortes de cada projecto alternativo, seja ele um jornal gratuito, por fax, por «e-mail» ou na Internet. $\mathrm{O}$ conhecimento do público-alvo e uma clara definição dos objectivos que se pretendem atingir são, por isso, indispensáveis.

Deixei aqui algumas ideias, mas muitas outras existem, algumas delas na minha gaveta, em forma de ante-projecto e à espera de quem me desafie a comigo pô-las em prática. $\mathrm{O}$ que digo aos jovens licenciados ou finalistas de Comunicação Social, das áreas de Jornalismo e/ou de Publicidade, é que não tenham receio e avancem com pequenos projectos de auto-emprego ou de parceria entre colegas.

Uma palavra também para os investigadores. Está aqui um campo que, julgo eu, não foi ainda suficientemente investigado. A imprensa alternativa tem uma história, uma evolução e muitas variantes que não se resumem às apresentadas. Disponham da minha modesta contribuição, se dela necessitarem. 